\title{
INTERNACIONALIZAÇÃO DO CONHECIMENTO CIENTÍFICO E A COMUNICAÇÃO ENTRE PESQUISADORES DE CAMPOS AFINS
}

A Revista Brasileira de Crescimento e Desenvolvimento Humano está consolidada como um periódico de escolha dentre os pares, em diversos campos do conhecimento humano. Ao longo do ano de 2010, publicou 47 artigos, dois anais de Congressos Internacionais e duas resenhas. A produção científica é proveniente de diversas partes do mundo. Recebemos mais de 140 artigos no ano de 2010, aos quais não conseguimos, ainda, dar o devido destino. A batalha é longa, o número de soldados reduzido e o trabalho oculto, de formiguinha.

Somos, de fato, um periódico multidisciplinar, que publica questões de Saúde Pública, Psicologia, Educação, Tecnologia, entre outras. No repositório de produção intelectual, os artigos têm trazido contribuições significantes para o avanço do conhecimento. Ao longo de seus 20 anos, a RBCDH é opção por conhecimento crítico, plural e arbitrado, pautado pela qualidade inerente ao perfil de seus criadores, lá na década de 90 , no século passado. Ser plural torna a $\mathrm{RBCDH}$ um repositório interdisciplinar plenamente comprometido com a qualidade do material nele publicado.

Ainda, é revista indexada em diversas bases de dados, entre as quais: DOAJ (Directory of Open Access Journals), LILACS (Centro Latino-Americano e do Caribe de Informação em Ciências da Saúde), CLASE (Citas Latinoamericanas em Ciências Sociales y Humanidades - Universidad Nacional Autonoma de Mexico - UNAM), Sociological Abstracts (Cambridge Scientific Abstracts), Social Services Abstracts, Linguistic \& Language Behavior Abstracts, Worldwide Political Science Abstracts, Index Psi Periódicos (BVS-Psi), Portal de periódicos da Universidade de São Paulo e Portal de Periódicos Eletrônicos de Psicologia (PePSIC), sendo que estes dois utilizam a metodologia SciELO (Scientific Electronic Library Online), modelo de publicação eletrônica de periódicos para países em desenvolvimento.

Com as ferramentas disponíveis no SciELO é possível versar os artigos da RBCDH para diversos idiomas (cinquenta e um), ou seja, os artigos publicados na revista podem ser acessados on line e no mundo todo. Somos, de fato e direito, periódico internacional, que cobre os cinco continentes e deles recebe suas contribuições intelectuais.

Neste número 20(3), publicam-se um artigo canadense, da Universidade de Toronto, e outros 14 de diversas regiões do Brasil. Há relatos de percepção corporal e atividade física em uma coorte de adultos jovens brasileiros, de pesquisadores de Ribeirão Preto, SP, os quais abordam temáticas atuais e relevantes no campo da saúde da criança e do adolescente, tais como satisfação corporal, imagem corporal, índice de massa corporal e atividade motora. Da cidade de Campinas, SP, há contribuição sobre funções apendiculares desencadeadas pela visão, em lactentes nascidos pré-termo e a termo. Ele sinaliza para a questão de os lactentes prétermo, com a idade corrigida, apresentarem aspectos motores qualitativamente diferenciados daqueles de termo.

Mais uma contribuição ao cenário da programação de modulações biológicas caracterizadas pelo nascimento pré-termo. De São Paulo, os leitores "degustarão" de importante trabalho com metodologia qualitativa versando sobre as práticas de aleitamento materno, com ênfase nos conhecimentos de trabalhadores de uma creche.

Não menos interessante e com valor de marcador biológico, temos o manuscrito oriundo da cidade de São Luis, MA, que versa sobre valor de predição da ultrassonografia cerebral em recém-nascidos pré-termo para alteração do desenvolvimento neuropsicomotor, aos 12 meses de idade corrigida. Do Rio Grande do Sul temos pesquisa que avaliou o desenvolvimento motor de crianças de zero a 18 meses de idade, por meio de instrumento validado e de uso rotineiro, a Alberta Infant Motor Scale, relacionando faixa etária e postura, caracterizando o desenvolvimento infantil, destreza motora e seus fatores de risco. 
De Vitória, ES, há importante achado sobre o desenvolvimento na Síndrome de Down, com destaque que o desenvolvimento ocorre com atraso, quando comparado ao de crianças com desenvolvimento neuropsicomotor típico. Indivíduos com Síndrome de Down possuem "tempo" e "espaço" próprios para a aquisição de marcos de desenvolvimento, ratificando a importância das estimulações em longo prazo para essas crianças, respeitando uma cronologia própria.

Do Acre observa-se contribuição intelectual no campo do baixo peso ao nascer (BPN) e fatores de risco a ele associados. O BPN é considerado um dos mais importantes problemas de saúde pública em todo o mundo, contribuindo substancialmente para a morbimortalidade infantil. Na sequência, pesquisa de Uberaba, $\mathrm{MG}$, traz abordagem sobre Bakhtin e os processos de desenvolvimento humano. Do Sul, de novo, outro artigo aborda o espaço da atenção básica, a unidade básica de saúde, como espaço lúdico para educação e promoção da saúde infantil. De Toronto, Canadá, temos pesquisa que norteará, não havendo dúvidas, avaliação e conduta em crianças com acúmulo de líquido peritoneal, fato comum naquelas com problemas abdominais, demonstrando que a causa é secundária ao aumento da permeabilidade vascular.

Da Região do ABC Paulista, os autores destacam a prevalência de enteroparasitas, evidenciando a necessidade de intervenção dos poderes públicos no controle e combate de endemias ambientais. Em Rio Branco, no Acre, as autoras abordam emergente assunto de crescimento e desenvolvimento, na fase do climatério, destacado-a como período da vida das mulheres marcado por inúmeras transformações e mudanças, que caracterizam o término do período reprodutivo.

Finalizando, há interessantes artigos sobre Saúde Bucal no Programa Saúde da Família, na perspectiva do usuário e outro tratando qualitativamente a questão do uso indiscriminado da pílula do dia seguinte, ambos da Cidade de São Paulo. Por fim, o número 20(3) da RBCDH publica artigo do Sul do País com abordagem sobre a depressão mater- na e autismo infantil. Trata-se de assunto ainda pouco discutido na literatura nacional e que o leitor terá a oportunidade de construir opinião sobre a temática, pois há evidências de intenso estresse nos cuidadores de crianças com autismo, especialmente nas mães, podendo levar ao desenvolvimento de um quadro depressivo materno. Como consequência, a depressão materna pode afetar tanto a mãe quanto a criança.

Estes conteúdos reforçam, assim, a defesa de conhecimento crítico, plural e arbitrado na construção de repositórios da ciência, tal qual é exigência do movimento do acesso livre ou Open Access. A RBCDH é parte integrante deste movimento.

Em franca evolução para uma facilidade cada vez maior de acesso, projeta-se para o ano seguinte a implantação da submissão on line, a progressiva disponibilização on line de artigos anteriores a 2005, ampliação do número de artigos publicados por ano e a sua marcação, desde a criação, com o Digital object identifier (DOI), que é um padrão para identificação de documentos na rede de computadores. Além disso, serão publicados sessenta artigos em três volumes por número, a partir de 2011.

Desta maneira, a Revista Brasileira de Crescimento e Desenvolvimento Humano continuará trazendo questões emergentes no mundo contemporâneo, como deve ser o papel de uma revista científica de qualidade. Espelhando como deve ser a prática da ciência: plural, acessível e facilitadora na divulgação das contribuições intelectuais. A RBCDH é uma revista internacional de fato e de direito, quer na circulação, quer no conteúdo publicado. Continuamos seguindo esses passos, por maiores que sejam as dificuldades impostas pelos obstáculos inerentes a este processo.

A ciência deve, sempre, pautar-se na verdade transitória, pois inexiste a verdade absoluta.

Que todos tenham uma leitura crítica e, portanto, proveitosa.

\section{Luiz Carlos de Abreu Editor Executivo}

